\title{
DA TECNOLOGIA DA INFORMAÇÃO À CONSTRUÇÃO DE UM CONCEITO DE SEGURANÇA
}

\author{
JOAO ROBERTO CAIXETA ${ }^{1}$
}

\author{
Programa de Pós-Graduação em Ciências da Linguagem \\ Faculdade de Filosofia, Ciências e Letras Eugênio Pacelli \\ Universidade do Vale do Sapucaí \\ Av. Pref. Tuany Toledo, 470 - 37550-000 - Pouso Alegre - MG - Brasil \\ roberto.caixeta@bol.com.br
}

\begin{abstract}
Resumo. $O$ presente trabalho tem como objetivo apresentar considerações sobre discurso e tecnologia na construção da ideia de 'proteção'. Para tanto, analisa o ideal disciplinar panóptico e, por extensão, os artefatos tecnológicos de vigilância, especialmente, as câmeras de segurança que se efetivam como mecanismos de monitoramento e controle das ações do sujeito. Sob a perspectiva da Análise de Discurso, articula a proposta de Foucault acerca dos mecanismos de controle, além das considerações de Pêcheux e Orlandi sobre discurso, sujeito e construção de sentido. Infere, assim, que sentidos de proteção se constituem em condições de produção específicas, passando a (res)significar o próprio sentido de segurança.
\end{abstract}

Palavras-chave: tecnologia; segurança; vigilância digital; sociedade de controle.

\begin{abstract}
The present work has as aim to present considerations about speech and technology in the construction of the idea of 'protection'. For that, it analyses the ideal panopticon discipline and, for extension, the technological vigilance products, especially the security cameras that become effective as mechanisms of monitoring and control of the actions of the subject. Under the perspective of Speech Analysis, it articulates Foucault's proposal about the mechanisms of control, also the considerations of Pêcheux and Orlandi about speech, subject and construction of meaning. It infers, so senses of protection are constituted in specific conditions of production, bringing another meaning for its own sense of security.
\end{abstract}

Keywords: technology; security; digital surveillance; society of control.

\section{Introdução}

A preocupação iminente do cidadão acerca da segurança corrobora os investimentos em aparatos de proteção, especialmente no que tange à tecnologia de informação, que oferece recursos cada vez mais sofisticados visando à coleta de dados e análise de informações, que, em tese, contribuem para tornar o espaço urbano mais

\footnotetext{
${ }^{1}$ Doutorando em Ciências da Linguagem (PPGCL-UNIVÁS). Professor no Instituto Federal de Educação, Ciência e Tecnologia do Sul de Minas Gerais - IFSULDEMINAS, Campus Machado (MG).
} 
seguro. Nessa gama de alternativas, disponibiliza-se desde câmeras de vigilância ininterrupta e conectadas a sistemas de análise de dados em alta resolução, até as sofisticadas tecnologias de reconhecimento facial que, configurando uma nova revolução tecnológica, estabelecem precedentes de vigilância contínua à medida que configuram comportamentos e ações pré-determinadas, delineando os contornos de uma sociedade de controle, como reitera Foucault (2002 [1975]).

Embasados por um pretenso conceito de proteção, assistimos a um modelo de segurança pautado na tecnologia, em que o controle estabelece um constante monitoramento sobre o indivíduo, remetendo-nos ao ideal de vigilância concebido por Jeremy Bentham (2000). Esse conceito de segurança pautada em aparatos tecnológicos pressupõe a anulação da identidade do indivíduo enquanto sujeito, pois este passa a ser representado por um número, um código, uma imagem ou meros dados identificáveis através de um sistema 'onisciente' que o condiciona a comportamentos ou condutas determinadas ou pré-estabelecidas.

Partindo desse pressuposto, conjectura-se: na atual sociedade da informação, a concepção de segurança pautada na utilização de um aparato tecnológico de monitoramento e coleta de dados pode legitimar ou potencializar uma sociedade de controle? Ainda que se disseminem as ideias de proteção e segurança, em que medida os mecanismos de vigilância, implementados pela tecnologia de informação, 'violam' ou deslocam os sentidos relacionados ao direito à privacidade e à liberdade do sujeito?

A partir dessa conjectura é que propomos uma reflexão acerca da contenção da violência em confluência com o conceito de segurança, o qual é estruturado a partir das inovações da tecnologia da informação, permitindo monitorar comportamentos à medida que os mesmos são normatizados e regulados e, por extensão, estabelecem-se as condições que dão sustentação às formulações e à construção de um discurso que condensa os ideais de proteção preconizados por uma sociedade refém do medo e da insegurança.

O presente artigo propõe considerações acerca da influência da tecnologia de monitoramento e vigilância nas práticas sociais. Como referencial teórico, acentuamos a perspectiva foucaultiana no que se refere aos mecanismos de controle do indivíduo, além da mobilização de conceitos da Análise de Discurso, de linha francesa, fundamentados nas considerações de Pêcheux e Orlandi, no tocante à constituição do sujeito, dos sentidos e sua possível (res)significação.

Os enunciados: "Sorria, você está sendo filmado" e "Vigilância monitorada 24h" configuram formulações que evidenciam dispositivos tecnológicos de monitoramento ostensivo. Sendo assim, os aparatos de vigilância, bem como os enunciados supracitados, constituem objeto de análise desse trabalho, pois constituem não apenas mecanismos de vigilância, mas também potencializam uma concepção de segurança à medida que impõem um caráter disciplinar e normatizador ao indivíduo. 


\section{2. "Sorria, você está sendo filmado": da tecnologia da informação à construção de um conceito de segurança}

Vivemos o ápice de uma era tecnológica que disponibiliza os mais variados instrumentos de comunicação e informação, os quais transformaram, sobremaneira, a rotina do indivíduo através da interação com essas múltiplas ferramentas. Orbitam nesse universo tecnológico celular, smartphone, iPhone, tablet, notebook, iPod, iPad, vídeo game, câmeras de altíssima resolução e todo um aparato vinculado ao mundo digital que, por sua vez, está diretamente conectado à rede mundial de computadores.

Se múltiplas são as ferramentas disponibilizadas pela tecnologia da informação, várias também são as possiblidades de rastrear, vigiar e traçar perfis de usuários, conforme atesta Bruno (2006). De acordo com a autora, uma série de ambientes e serviços disponíveis no ciberespaço contém em seus sistemas de funcionamento meios de monitorar as ações dos indivíduos, estabelecendo uma vigilância, na maioria das vezes, desconhecida ou desconsiderada pelos usuários. Esses dispositivos de monitoramento digital, segundo Bruno (2006), constituem motivo de preocupação e demandam reflexões, visto que configuram um atentado à privacidade à medida que se tornam tecnologias de vigilância potenciais.

Terceiro (1996) também ressalta esta captura de informações derivadas do monitoramento das ações cotidianas das pessoas, reiterando que esses dados serão utilizados tanto para oferecer outras mercadorias e/ou serviços ou até mesmo para compor bancos de documentos, os quais poderão ser consultados por variados órgãos, especialmente, se essas informações contiverem elementos relativos à segurança.

Os dados pessoais capturados na rede mundial de computadores, comumente, são usados para alavancar o mercado de informações sobre usuários, as quais são utilizadas pelo departamento de marketing das empresas para fins comerciais. Terceiro (1996), porém, adverte para o surgimento de outro "nicho" comercial advindo das práticas de monitoramento digital. O autor destaca que o serviço de vigilância e captura de informações sobre os usuários na rede mundial de computadores potencializa o surgimento de um subproduto automático suscetível de utilização e comercialização. Segundo Terceiro (1996), o atentado à privacidade das pessoas que supõe o recolhimento de dados provoca sérias preocupações em relação à proteção, confiada a técnicas de encriptação que, até bem pouco tempo, pertenciam ao clandestino mundo da espionagem, sendo hoje moeda corrente no mundo digital.

A tecnologia de informação - aliada à captura de dados sobre os usuários - é tão sutilmente estruturada e articulada que o indivíduo convive com certa "naturalidade" em meio a essa profusão de instrumentos de monitoramento. Estar sendo monitorado ou ser vítima de vigilância contínua é algo que, paulatinamente, vai se incorporando ao nosso dia a dia, pois vivemos sob a égide da sociedade das inovações e informações tecnológicas. Sendo assim, a presença de câmeras de segurança passou a integrar o cotidiano das pessoas. Nos lugares mais estratégicos, explícitas ou camufladas, elas se efetivam no nosso dia-a-dia, padronizando comportamentos e desenvolvendo uma prática de monitoramento e coerção, conforme explicitam Gundalini e Tomizawa (2013). 
Ao integrarem o cotidiano das pessoas, as câmeras de segurança, bem como todo o aparato tecnológico da indústria da segurança, pressupõem espontaneidade em sua aceitação, enquanto mecanismos de monitoramento das práticas sociais. Assim sendo, o enunciado "Sorria, você está sendo filmado", produz um efeito de sentido (via "sorria") de cumplicidade e até mesmo de resignação do sujeito vigiado, visto que ele deve aceitar esse processo de coerção e cerceamento de sua liberdade "sorrindo". Espera-se do indivíduo que os artefatos de segurança sejam aceitos com naturalidade, visto que, hipoteticamente, preconizam instrumentos que visam à proteção do sujeito e, como tal, não devem causar a ele nenhum incômodo ou estranhamento.

Nesse contexto, incorrendo à subjetividade advinda da licença poética, aludimos ao pensamento de Guimarães Rosa, em "Grande Sertão: Veredas", quando o autor sentencia: "Deus existe mesmo quando não há. Mas o demônio não precisa de existir para haver - a gente sabendo que ele não existe, aí é que ele toma conta de tudo" (ROSA, 1976, p. 49). Reservadas as devidas proporções, conjecturamos, por analogia, que, se a artimanha do demônio é passar despercebido, reforçando a ideia de que ele não existe, pois assim tem facilitado o exercício de seu domínio, conforme salienta Guimarães Rosa, aludimos, metaforicamente, que os mecanismos tecnológicos de segurança notadamente, as câmeras de vigilância -, ao sugerirem essa cumplicidade, incitam certa conivência ou até mesmo naturalidade do indivíduo diante desses mecanismos de monitoramento. Quem sabe, talvez, na esteira de Guimaraes Rosa, ousamos parodiar: "a gente se acostumando ou fingindo que os artefatos de vigilância não existem, aí é que eles tomam conta de tudo".

Acerca da vigilância que se operaria sobre a sociedade do futuro, o escritor inglês George Orwell, em 1948, anteviu, no livro “1984” (Nineteen eighty-four), que as pessoas seriam vigiadas e controladas por câmeras, sendo que as mesmas ficariam sob o monitoramento constante de uma televisão denominada de "O Grande Irmão".

Conforme preconizoua Orwell (1978), é possível registrar comportamentos, monitorar hábitos, capturar informações graças ao sistema de vigilância e espionagem engendrado a partir da tecnologia da informação, de forma que se confrontam os limites entre o público e o privado. Seduzido pela tecnologia e, por conseguinte, pela internet, o usuário é, literalmente, capturado pelas "redes" sociais; contudo, a aparente ideia de naturalidade (e neutralidade) serve apenas para camuflar e atenuar um complexo sistema de gerenciamento no qual, pela tecnologia, estabelece-se um eficiente projeto de monitoração eletrônica, em uma sociedade cada vez mais "acostumada" ou induzida a práticas de vigilância.

Ao conectar-se à internet, o sujeito passa a ser mapeado ou monitorado e, sobre esse propósito, faz-se pertinente o pensamento de Foucault (2002 [1975]), ao atestar que, quanto maior o número de informações em relação aos indivíduos, maior a possibilidade de controle do comportamento dos mesmos.

O enunciado "Sorria, você está sendo filmado", tão recorrente em nosso cotidiano, ao mesmo tempo em que explicita ao sujeito a prática do monitoramento, também cria um efeito de sentido de que esse monitoramento visa à sua segurança. $\mathrm{O}$ imperativo "sorria" ordena que o sujeito "relaxe", "baixe a guarda", pois o sorriso seria a senha para avalizar a prática de vigilância em questão. Ressalta-se também a ironia em 
funcionamento nesse dizer, pois as pessoas costumam sorrir quando filmadas ou fotografadas, mas não em situações de vigilância. Assim, quando utilizado para indicar a presença de aparatos de vigilância, esse enunciado adquire e produz outros efeitos de sentido.

E, no que se refere ao monitoramento através da utilização de câmeras, a cidade de São Paulo é a mais monitorada do Brasil. A Revista Security Brasil, especializada em segurança privada e eletrônica, em sua versão on-line, destaca os dados divulgados pela ABESE (Associação Brasileira das Empresas de Equipamentos Eletrônicos de Segurança), de que há cerca de 1 milhão de câmeras de segurança na cidade de São Paulo, o equivalente a um aparelho de monitoramento para cada 7 pessoas. Esses dados também são confirmados pelo SIESE-SP (Sindicato das Empresas de Sistemas Eletrônicos de Segurança do Estado de São Paulo), que reitera a expectativa de que esse número dobre nos próximos anos.

Assim, paulatinamente, institui-se um conceito de segurança pautado na vigilância e no monitoramento do indivíduo, à medida que se amplia a capacidade de capturar informações, coletar e armazenar dados em função de uma pretensa ideia de proteção que se efetiva pelo monitoramento e consequente disciplinarização do sujeito.

\section{Ver, vigiar e disciplinar: a tecnologia do poder}

A tecnologia direcionada à vigilância procura se justificar no combate à violência e no pretenso intuito de coibir as ações que possam comprometer a segurança do indivíduo. Porém, estas medidas de combate à violência e de manutenção da segurança por meio de estratégias de monitoramento interferem diretamente nas práticas sociais, visto que partem do princípio de que atitudes "desejáveis" são aceitas, ao passo que as "indesejáveis" e, portanto, não aceitas, são dignas de intervenções ou punições.

Colocamos em xeque esse projeto de sociedade em que se exerce um poder disciplinar sobre o indivíduo através de dispositivos de vigilância e, por analogia, aludimos ao modelo panóptico de monitoramento concebido pelo filósofo inglês Jeremy Bentham, no século XVIII. Esse modelo de prisão, baseado em uma vigilância ininterrupta, em muito se assemelha ao arquétipo de sociedade vigiada e monitorada que temos na contemporaneidade. $\mathrm{O}$ termo panóptico ( $\mathrm{pan}=$ tudo / óptico = visão) acentua a ideia de abrangência da visão ou o controle total sobre o indivíduo, ou seja, projetava-se uma vigilância ampla e ininterrupta da qual não se poderia fugir.

Muitos conceitos de panóptico são aplicados ao modelo contemporâneo de segurança, pois, o mesmo é pautado na vigilância e na normatização de comportamentos através da tecnologia. Se no panóptico havia a ideia de um vigilante que exercia o poder através da onipresença, conceito semelhante é desenvolvido pelas câmeras ao causar um efeito psicológico de vigilância permanente, em que o cidadão acredita que está sendo observado por olhos igualmente oniscientes e onipresentes, tal qual no projeto idealizado por Bentham (2000). 
Em ambos os modelos de vigilância preconiza-se um monitoramento de maneira indistinta, de forma que não se objetiva apenas a mera observação, mas também a coibição das ações do indivíduo à medida que se regulam as atitudes, estabelece-se os padrões de comportamento desejados e criam-se regras de controle social, mediante a disciplinarização do sujeito a mecanismos de controle que lhe são determinados.

Estabelecer instâncias de poder e controle a fim de padronizar comportamentos em função de uma pretensa "ordem social" é algo intrínseco à organização e manutenção da sociedade. Inúmeras são as situações em que, a fim de exercer o poder sobre o sujeito, um conjunto de normas e padrões é estabelecido, que passam a alicerçar a sociedade com pauta em valores morais, religiosos, éticos, políticos ou culturais, conforme salienta Althusser (1987 [1971]).

Sendo assim, desde as sociedades primitivas, bem como ao longo da história da humanidade, o comportamento humano é determinado mediante métodos que configuram o poder sobre o sujeito. Esse poder se constitui à medida que permite disciplinar, controlar e estabelecer a sujeição do indivíduo, ao qual são impostas as regras de conduta social, em suas variadas instâncias, de forma que o mesmo possa ser contido, docilizado e, sobretudo, controlado, conforme salienta Foucault (2002 [1975]).

Nesse contexto, percebe-se, em épocas distintas, em diversas civilizações ou sociedades, a implementação de dispositivos ou instrumentos visando à regulação do indivíduo, bem como ao controle social, preconizando comportamentos considerados adequados e, portanto, aceitáveis. De acordo com Scuro (2000), esferas semelhantes de manutenção do poder e de controle sobre a sociedade são perceptíveis nas dinastias dos faraós, no império romano, assim como na estrutura feudal, em que prevalecia a autoridade absoluta do rei, acima de qualquer código, conceito ético ou princípio legal.

A partir do Século XVIII, com o advento do Iluminismo, as relações entre o indivíduo e o poder instituído passaram por profundas transformações, decorrentes daquele novo contexto político, no qual o controle social centralizado e legitimado exclusivamente na aspiração do rei já não mais se justificava. Era imperiosa uma reestruturação das esferas de poder naquele incipiente conceito de sociedade, mediante novos instrumentos normatizadores e reguladores do indivíduo em suas práticas sociais, conforme salienta Scuro (2000).

O autor supracitado ressalta que, naquele contexto, emergiria a figura do Estado, enquanto instância central de vigilância e controle, ocupando um espaço que outrora era exercido pelo absolutismo monarca. Dentre os novos dispositivos de controle estatal, há que se ressaltar o sistema jurídico, através do qual seriam assegurados os princípios democráticos, assim como os direitos (e deveres) inalienáveis ao indivíduo.

Nesse contexto, incorre-se no paradoxo: o Estado - principal mantenedor do direito democrático - é o mesmo encarregado pela articulação das ferramentas jurídicas e, por extensão, também é responsável pelos instrumentos de sujeição e vigilância do indivíduo; este que, por sua vez, submete-se a sanções ou punições preestabelecidas pelo controle estatal. 
Nesse contexto, mobilizamos o pensamento de Althusser (1987 [1971]), ao considerar o Estado enquanto um aparelho repressivo e amparado por uma superestrutura jurídico-política e ideológica, que, naquele novo contexto social, utilizou-se do precedente legal a ele imputado pela administração, pelo exército, pela polícia, pelos tribunais, pelas prisões a fim de que fosse assegurada a implantação dos aparelhos ideológicos de Estado, ou seja, para que os dispositivos de controle e disciplinarização do indivíduo se mantivessem, ainda que mascarados pela nova hierarquia social instaurada.

Dessa forma, segundo Althusser (1987 [1971]), através do Estado, a classe dominante montou um aparelho de coerção e de repressão social, que lhe permitiu exercer o poder sobre toda a sociedade, fazendo-a submeter-se a regras políticas. Para o referido autor, o grande instrumento do Estado é o Direito, isto é, o estabelecimento de leis que regulam as relações sociais em proveito dos dominantes. Através do Direito, o Estado aparece como legal, ou seja, como "Estado de direito". A dominação de uma classe é substituída pela ideia de interesse geral encarnada pelo próprio Estado.

Em suma, o Estado se efetiva como força de execução e de intervenção repressiva a serviço da classe dominante. Em nome de uma "pretensa segurança" ou manutenção de direitos democráticos, estabelecem-se discursos, impõem-se mecanismos e procedimentos de interdição, violência, vigilância e controle sobre o indivíduo.

Ao longo da história, diversos modelos de controle, bem como variados métodos de vigilância foram implantados tendo em vista a submissão do indivíduo a normas que, uma vez assimiladas, seriam incorporadas às práticas sociais. Dessa forma, paradigmas foram estabelecidos tendo em voga a disciplinarização e a subserviência de um sujeito, cujo comportamento era "moldado" mediante um sistema hierárquico e/ou político, notadamente centrado no Estado, que preconizava uma sociedade disciplinar, especialmente a partir dos séculos XVIII e XIX, conforme salienta Scuro (2010).

Além do conceito de poder centralizado no Estado, outro fator relevante foi o advento da Revolução Industrial, que engendrou emergentes relações sociais, além de suscitar novas esferas de poder disciplinar, visto que, naquele contexto, emergia a figura do proletário, aquele sujeito operário que, em si, traduzia não apenas a força de trabalho, mas também representava o principal mecanismo de produção e, assim, consequentemente, o lucro. Portanto, o trabalhador potencializava, duplamente, uma necessidade de controle e disciplinarização, instaurando o poder disciplinar pela visibilidade, pelo controle, vigilância e regulação ininterrupta de suas ações, conforme atesta Foucault (2002 [1975]), referindo-se àquela sociedade disciplinar dos séculos XVIII e XIX.

Ao conjecturar as relações de poder e vigilância sobre o indivíduo, notadamente, a partir do Iluminismo e da Revolução Industrial, mobilizamos novamente o arquétipo do panóptico de Bentham, considerando o pensamento de Foucault (2002 [1975]), pois, nessa intrínseca relação, o referido autor salienta que, na sociedade moderna, os mecanismos e dispositivos de vigilância não só aperfeiçoam o exercício do poder, como também estabelecem uma sociedade disciplinar na qual se permite, através de um controle "onisciente", vigiar, monitorar, identificar, qualificar, registrar, classificar e, se necessário, punir. 
Foucault (2002 [1975]) salienta que o panóptico funciona como uma espécie de laboratório de poder, pois, graças a seus mecanismos de observação, ganha em eficácia e em capacidade de penetração no comportamento dos homens. Assim, no final do século XVIII, através de uma vigilância ostensiva, o panóptico permitiu não apenas engendrar o poder, mas também aperfeiçoá-lo, pois estabeleceu um controle por meio do qual o indivíduo não precisava saber que estava sendo observado, mas precisava ter a certeza de que poderia ser, a qualquer momento. Dessa forma, o panóptico, à medida que era visível, ao mesmo tempo, era inverificável.

Nessa confluência, associamos o conceito de controle e monitoramento empreendido pelo panóptico aos mecanismos e práticas de vigilância com os quais convivemos na sociedade contemporânea. Assim, os dizeres: "Sorria, você está sendo filmado" e "Vigilância monitorada 24h" traduzem, em si, o modelo de controle onisciente tal qual pressupunha Bentham (2000). Evidencia-se um conceito de vigilância ininterrupta, traduzido por mecanismos de caráter psicológico, onde não se pode identificar quem a executa, mas cria-se o efeito de observação contínua, na qual se sobrepõe um ideal de ordem pela disciplinarização e imputado pela monitoração eletrônica ostensiva.

Assim, como no ideário do panóptico, em que a essência do poder se evidencia na constante e total sujeição do indivíduo ao controle, conforme atesta Foucault (2002 [1975]), por analogia, ressaltamos a relação que ocorre entre o sujeito e a ocupação do espaço social, analisando o atual conceito de segurança e considerando os mecanismos tecnológicos de proteção, especialmente no que tange ao sistema de monitoramento por câmeras.

Ao considerar as novas tecnologias da informação como fator de segurança, mediante o controle ininterrupto do comportamento do sujeito em suas práticas sociais, infere-se que tal princípio constitui um paradoxo, visto que se constrói uma ideia de "proteção", contudo, o que se observa é a imposição de um regime de poder disciplinar que, contraditoriamente, pressupõe o direito "inalienável" à liberdade, fazendo deslocar o seu real sentido. Ou seja, o indivíduo é "livre" desde que se comporte conforme modelos identificáveis de conduta em um sistema de vigilância que está apto a identificar, reconhecer e interpretar "movimentos suspeitos". Em suma, em favor de uma pretensa ideia de proteção e segurança, abdica-se do direito à liberdade individual nas práticas sociais.

Porém, esse arsenal disponibilizado pela tecnologia da proteção não pode ser passivamente incorporado à rotina do sujeito, visto que, envoltos por um conceito de transparência e neutralidade, dissimulam-se conflitos de ordem política, ética e moral, e, por conseguinte, de caráter social, quando consideramos o impacto provocado pelos dispositivos tecnológicos de segurança que, indubitavelmente, fundamentam-se nos princípios verbais: ver, vigiar e disciplinar, conforme salienta Foucault (2002 [1975]). 


\section{Câmeras de segurança: um panóptico vigilante e onipresente}

No Brasil, assiste-se a uma crise no sistema de segurança pública, agravada pela proliferação da criminalidade e a banalização da violência, face à inoperância do Estado, que falha no seu papel como articulador de políticas de proteção.

Diante da incapacidade do Estado em coordenar políticas efetivas e eficientes de segurança, o indivíduo recorre a dispositivos, tais como: cães, grades, altos muros, alarmes, cercas elétricas, câmeras e até os mais sofisticados equipamentos, movimentando um mercado impulsionado pelo medo e pela pretensa ideia de proteção, pautada na vigilância ostensiva.

Nessa conjuntura, aludimos a Orlandi (2005), ao acentuar que, no que concerne à segurança, o seu sentido se configura justamente pela ausência quando se evidencia, sobretudo, a falha do Estado na implementação de políticas públicas, visto que ele se credencia como mantenedor desse direito, bem como o principal articulador da vida social. Nesse contexto, diante da falha do Estado e da ineficiência de políticas públicas de segurança, implantou-se uma "indústria da segurança" na qual são oferecidos os mais variados implementos e inovações tecnológicas que, por sua vez, impactam a vida das pessoas, especialmente, no que tange às interações e às práticas sociais.

A partir dessas concepções, questionamos a relação entre a tecnologia da informação - notadamente direcionada à segurança - e o sujeito, destacando a forma como ela se efetiva, como interfere no convívio social e, principalmente, como tais princípios acabam por ferir as questões éticas ao estabelecer um modelo de monitoramento e vigilância. Reiteramos que, nessa relação antagônica, a tecnologia da segurança contribui para ressignificar as relações sociais, moldando ou adequando comportamentos a padrões determinados, tornando o sujeito subserviente à técnica.

É pertinente destacar o pensamento de Winner (1987 [1986]), ao acentuar que a experiência da sociedade moderna nos mostra que as tecnologias não são simples meios para as atividades humanas, mas poderosas forças que atuam para dar nova forma à dita atividade e ao seu significado. Segundo o autor, a classe de coisas que tendemos a considerar meras entidades tecnológicas se fazem problemáticas, se começamos a observar a grande influência que exercem nas condições de vida social e moral.

Diante desse pressuposto, reiteramos que a tecnologia vem determinando o comportamento social, notadamente, no que se refere à questão da segurança, à medida que disponibiliza um aparato de ferramentas ou mecanismos de controle propriamente ditos. Seduzida pelos apelos da tecnologia, a sociedade se coloca em uma situação de letargia, a qual Winner (1987[1986]) nomeia como um "sonambulismo tecnológico", referindo-se ao conformismo ou passividade diante das ferramentas tecnológicas, visto que há uma aceitação da "marcha do progresso" sem que haja um posicionamento crítico e reflexivo sobre as consequências desse processo de submissão a artefatos científicotecnológicos que impactam, sobremaneira, a vida dos sujeitos.

Winner (1987[1986]) alude que tal situação é responsável por definir novos padrões de conduta, bem como por estabelecer novos comportamentos a partir do uso e da aceitação irrefletida das tecnologias e de seus artefatos. No que concerne à questão da 
tecnologia de monitoramento, há um considerável arsenal de ferramentas de gerenciamento do sujeito em suas práticas sociais e, conforme salienta Winner (1987[1986]), o que importa não é a tecnologia em si, mas o sistema social ou econômico no qual ela está inserida. Para o referido autor, as tecnologias são moldadas pelas forças sociais e econômicas, sendo que os dispositivos tecnológicos quase sempre se ligam a formas específicas de organização de poder e autoridade.

Se, em determinadas épocas da história, a vigilância sobre o sujeito se deu pela ação da família, do rei, da igreja, do patrão e do Estado, atualmente, extrapola-se o limite do espaço público e privado frente às inovações tecnológicas que potencializam múltiplas formas de gerenciamento das ações do sujeito - suplantando as dimensões éticas - ao oferecer uma gama de ferramentas voltadas a esse controle. Dentre esses artefatos, destacamos o "Google Street" e também a proliferação das câmeras de segurança que, potencialmente, ilustram a reflexão até aqui empreendida.

O "Google Street View" é munido de ferramentas que disponibilizam imagens tridimensionais possibilitando vistas panorâmicas de 360 graus, através de um serviço de busca que mapeia e captura informações sobre ruas, avenidas e praças de diversas cidades do mundo, utilizando-se de um sofisticado sistema de tecnologia de geolocalização.

Envolvido em polêmicas desde o seu lançamento na internet, em maio de 2007, o "Google Street View" captura imagens - adjuntas de dados pessoais - que, potencialmente, atentam contra o direito do cidadão à privacidade. Esse aplicativo constitui uma potente ferramenta de vigilância e controle, visto que possibilita, através de imagens em altíssima resolução, a identificação de residências, automóveis, estabelecimentos comerciais e até mesmo de pessoas em situações consideradas impróprias ou vexatórias, resultando em processos por uso indevido de imagem, divulgação de dados pessoais e, sobretudo, por invasão de privacidade. Desencadeia-se, assim, uma discussão sobre os limites éticos sobre o recolhimento de dados à revelia ou sem autorização do sujeito alvo dessa ação invasiva.

Como forma de atenuar esse problema, a empresa multinacional de tecnologia passou a utilizar um processo em que as placas dos veículos e o rosto das pessoas são desfocados de forma que, "em tese", garante-se o anonimato. Essa captura de imagens constitui um desdobramento das inúmeras ferramentas de cunho invasivo que a tecnologia possibilita. Ao desfocar informações pessoais, bem como a fisionomia das pessoas, a empresa assume - por extensão dessa ação - que há a consciência de um ato ilegal praticado, além do reconhecimento de uma invasão deliberada à liberdade e à privacidade. Assim, as imagens "desfocadas" adquirem o caráter de legalidade ainda que se mantenham questionáveis os princípios éticos dessa ação.

Tais procedimentos na captura de dados, divulgação de imagens e informações pessoais estabelecem um precedente que atenta contra a liberdade individual e deve suscitar reflexões sobre os limites e a ética na utilização da tecnologia, posto que, desprovidos de visão crítica acerca desse tema, assistimos passivamente ao cerceamento da privacidade como preconizou Winner (1987 [1986]), sucumbindo-nos, submissos, à doutrinação imputada pelas inovações tecnológicas. 
Outro aspecto relevante a essa reflexão é a proliferação das câmeras como consequência da crescente preocupação com a segurança, visto que as estatísticas divulgadas pelos meios midiáticos atestam a elevação nos índices de violência no Brasil e corroboram a apreensão da sociedade em relação à proteção.

Considerando os dados divulgados pela ABESE (Associação Brasileira das Empresas de Equipamentos Eletrônicos de Segurança), de que há cerca de um milhão de câmeras de segurança na cidade de São Paulo, aludimos à íntima relação que se estabelece entre o sujeito, a insegurança, a vigilância e a tecnologia. Dentre os aparatos disponibilizados pela indústria da segurança, o serviço de monitoramento por câmeras é o que mais se popularizou, de forma que se incorporou ao cotidiano das pessoas. Esse método de vigilância ininterrupta delineia um projeto político de uma sociedade de controle, na qual cada movimento do indivíduo é capturado e passível de análise, visto que é submetido a padrões de aferimento preestabelecidos e considerados "normais" ou em consonância com as atitudes e comportamentos "desejáveis".

As câmeras de segurança traduzem em si formulações que permeiam um préconstruído, pois esboçam uma ideia de vigilância e monitoramento contínuo reforçando o conceito de que a tecnologia permite registrar as ações durante 24 horas ininterruptas, além de favorecer o arquivamento para posterior análise. Assim, a vigilância ostensiva se sobrepõe à ação humana no que tange à função de monitorar, registrar ou identificar situações que, em tese, possam comprometer o ideal de segurança, uma vez que o vigilante se baseia nas impressões provocadas pelo momento, pautando-se na subjetividade. Esse monitoramento "humano" é suscetível a falhas tanto no que se refere ao conceito de vigilância, propriamente dito, como também por não favorecer a possiblidade de identificação, reconhecimento e registro visando a posteriores análises comprobatórias.

Considerando que as câmeras de segurança se fundamentam na quantidade de informações capturadas, assim como na capacidade de acumular dados, tais procedimentos permitem acionar o conceito de memória metálica empreendido por Orlandi (2011), que a preconiza como aquela produzida pela mídia, pelas novas tecnologias de linguagem, constituindo-se como "a memória da máquina", da circulação, aquela que não se produz pela historicidade, mas por um construto técnico. Segundo a autora, por constituir-se como memória técnica, sobressai-se o paradigma da produtividade, da repetição e do acúmulo, visto que o mito desta forma de memória é o "quanto mais, melhor".

Ainda incorrendo a esse princípio destacado por Orlandi (2011), acerca da memória frente às novas tecnologias de linguagem, Mendonça (2004) ratifica que, enquanto a memória histórica está sujeita à falha, a metálica só produz o mesmo, isto quando a concebemos enquanto elemento de um artefato tecnológico.

Nessa conjectura, destacamos a percepção das câmeras de segurança, além do conceito da mecanicidade do objeto, mas, no instante em que a simples "presença" delas remetem a um pré-construído no imaginário coletivo, acionado por uma memória discursiva, a qual mobiliza a ideia de que a vigilância eletrônica é um sistema que não empreende falhas, à medida que estabelece uma relação de monitoramento ininterrupto e ostensivo, elemento esse que é responsável por provocar a coerção e a intimidação do 
sujeito. Observa-se, por esse aspecto, que ocorre uma formulação discursiva na qual as câmeras de segurança não mais exercem apenas a função de "segurança", de acúmulo de informações ou registro, mas também a função de intimidação.

É conveniente ressaltar a utilização de "câmeras cegas", equipamentos que não se prestam à função de vigiar ou registrar; são protótipos similares que visam apenas à intimidação ao explorarem esse pré-construído, pois há, na memória discursiva, uma formulação de que a presença de uma câmera de segurança empreende ideia de monitoramento, fator suficiente para intimidar ou inibir as ações do sujeito, apenas pela memória ligada ao sentido de presença atribuída a essa ferramenta. Caracteriza-se, assim, uma metodologia que visa à homogeneização de sentidos, cristalizando um conceito de segurança pela vigilância e, sobretudo, pela ideia de repressão e coerção, em que um aparato tecnológico determina o comportamento e interfere sobremaneira nas práticas sociais.

Enunciações como "Sorria, você está sendo filmado" e "Vigilância monitorada 24 h" instituem um efeito de sentido em que se fundem dois conceitos antagônicos: você está sendo vigiado $X$ tranquilize-se, pois, isso é para seu bem e segurança. Esse olhar eletrônico sobre as ações cotidianas do indivíduo caracteriza o mecanismo de controle instaurado na sociedade contemporânea. Através da intimidação ocasionada pela proliferação de ferramentas tecnológicas de vigilância, instaura-se um ideal de uma sociedade pautada em sanções normalizadoras impostas pelos mecanismos de vigilância. Assim, pretende-se "interpretar" os movimentos, reconhecer as atitudes consideradas "suspeitas", além de regular o sujeito, impondo-lhe padrões de comportamento social.

Especificamente, o enunciado "Sorria, você está sendo filmado" produz efeito de transparência da língua ao denotar a ideia de que, pela vigilância, a segurança se efetiva e se justifica. O discurso apresentado como neutro e não contaminado pela ideologia, na verdade, faz parte de um jogo discursivo onde se tenta produzir a evidência de que vigilância e segurança convergem para uma relação sinonímica. Mas, é justamente no equívoco (PÊCHEUX, 1978 [1969]) e na opacidade da língua que se ressalta, nessa formulação, o viés que visa à legitimação de um mecanismo de vigilância, controle e sujeição.

Considerando as condições de produção em que esse enunciado foi constituído, salienta-se que ele recorre a um pré-construído - que faz parte de uma memória discursiva - em que o verbo "sorrir" (ainda que no imperativo) implica uma situação de descontração, um momento de lazer ou de tal importância que deve ser registrado e imortalizado em uma fotografia.

Como paradoxo, ao ser empregado em situação de monitoramento, configura-se uma formação discursiva (PÊCHEUX, 1988 [1975]) em que o equívoco e a contradição constituem o modo de funcionamento do discurso de vigilância e "segurança", e, por extensão, estruturam a produção de efeitos de sentido. Considerando Pêcheux (1988 [1975]), convém salientar que o enunciado "Sorria, você está sendo filmado" promove uma atualização da memória discursiva, provocando deslocamento de sentido, pois pressupõe que o sujeito saiba que deve manter uma conduta conforme os padrões sociais a ele imputados e não sorrir para o artefato de vigilância. 
Analisar esse movimento de sentido e/ou significação é considerar o movimento do sujeito subordinado à materialidade da língua, ao processo histórico-social, assim como ao próprio processo de interpelação/identificação do indivíduo em sujeito. Nesse contexto, acentua-se que o enunciado "Sorria, você está sendo filmado" remete a uma formação discursiva que, por sua vez, está filiada a formações ideológicas que atuam na interpelação do sujeito, frente à sua necessária inscrição em práticas sociais (PÊCHEUX, 1988 [1975]).

Dessa forma, evidencia-se que o enunciado em questão articula e mobiliza sentidos de proteção, mas, por antagonismo, dissimula os traços daquilo que o determina, ou seja, a sustentação de mecanismos de monitoramento e controle das ações do sujeito, ao inscrever o verbo "sorrir" em uma formação discursiva que interpela, domina e, ideologicamente, o constitui sujeito. Tendo em vista as considerações de Pêcheux (1978 [1969]) e Orlandi (2011) sobre discurso, sujeito e construção de sentido, inferimos que sentidos de proteção se constituem em condições de produção específicas, passando a (res)significar o próprio sentido de segurança.

Em suma, há um mascaramento do discurso de monitoramento que se apresenta como neutro e transparente, produzindo evidência de segurança e proteção quando, na verdade, está impregnado de efeitos de sentido que revelam o funcionamento de mecanismos de vigilância, controle e disciplinarização, conforme salienta Foucault (2002 [1975]).

Considerando que as câmeras de segurança constituem ferramentas tecnológicas que demandam exercício de compreensão dos dados e imagens capturadas, no que se refere a esse processo de interpretação de movimentos ou comportamentos, recorremos a Pêcheux (1978 [1969]) situando que os gestos pertencem ao campo do simbólico. Portanto, quando se alia os gestos à interpretação, produz-se, consequentemente, "gestos de interpretação" que atuam como formas de interferência no cotidiano do indivíduo e, notadamente, em suas práticas sociais, conforme acentua Orlandi (1996).

Ancorados nesses pressupostos, aludimos aos efeitos de sentido produzidos pelos gestos de interpretação quando consideramos as novas tecnologias e os deslizamentos que são produzidos a partir de diferentes materialidades, pois, segundo Orlandi (2010), ainda que seja virtual, o espaço digital tem sua materialidade e produz efeitos. Para a autora, os dados equivalem a fatos de linguagem e estes, por sua vez, apresentam diferentes materialidades significantes que, na sua especificidade, apresentam modos distintos de significar. Assim, os fatos de linguagem transformam-se em informações abertas às diferentes formas de significar e produzir efeitos de sentido.

Quando consideramos as condições de produção que possibilitam tais formulações, enfatizamos o espaço urbano saturado por uma crise no sistema de segurança, a proliferação da criminalidade, bem como a banalização da violência que, por sua vez, estabelece na sociedade a sensação de medo e insegurança. O espaço urbano concebido como lugar de convivência social e ambiente de interação com outros indivíduos é pensado na dimensão de lugar onde o outro representa uma ameaça. A introdução do objeto tecnológico enquanto ferramenta de vigilância, nesse espaço, adquire a compleição de que se condensam os ideais de toda uma sociedade, assim como se justificam as medidas de coerção e controle social. Dessa forma, possibilita-se a 
formulação de um discurso de segurança pautado na vigilância e no monitoramento e, sobretudo, na padronização de costumes considerados "desejáveis" ou "aceitáveis", visto que há um sujeito a ser "contido", há um indivíduo a ser docilizado.

Considerando que sujeito e sentido se constituem ao mesmo tempo, Orlandi (2010) ressalta que o sujeito, ao significar, significa-se. Nessa perspectiva, diante das práticas de vigilância empreendidas pelos artefatos tecnológicos de monitoramento, aludimos à contradição que se estabelece em um indivíduo afetado pela ideologia, individualizado pelo Estado - e suas instituições - e interpelado pela linguagem, a qual não é transparente, notadamente, a tecnológica, para a qual o homem moderno é visto como objeto da tecnologia e delineado como produto da disciplina, estando, assim, condicionado a mecanismos disciplinares, conforme salienta Foucault (2002 [1975]).

A partir do pensamento de Foucault (2002 [1975]), evidenciam-se, segundo Fonseca (2011), as relações de poder cada vez mais "anônimas e funcionais", nas quais o indivíduo é submetido a observação, fiscalização, medidas comparativas, aferição de atitudes e comportamentos que são implementados pelas ferramentas tecnológicas de vigilância e monitoramento do homem contemporâneo. Ressaltando a contradição que se estabelece a partir desse contexto, Orlandi (2010) reitera a existência de uma forma sujeito individualizada, pautada em antagonismos, pois, à medida que se configura um sujeito livre e determinador, ao mesmo tempo, por confluência, há um sujeito submisso e determinado por uma ideologia.

Diante desses pressupostos, ao considerarmos o conceito de segurança pautado em mecanismos tecnológicos de vigilância, caracterizamos uma dicotomia segundo a qual o indivíduo abdica do direito fundamental à liberdade em troca da pretensa ideia de proteção. Subordinando-se a essas estruturas de controle, o indivíduo passa por um processo de descaracterização e apagamento de sua individualidade constitutiva, pois, nesse contexto, não há mais sujeito, mas corpo, a ser monitorado em meio a uma massa - um coletivo - submetida a padrões de comportamento passíveis de serem mensurados.

Ancorados nessas conjecturas, destacamos a tênue relação que se estabelece entre o indivíduo e as novas tecnologias de vigilância que, ao se efetivarem como estratégias de segurança, consolidam-se como estruturas de monitoramento, controle e normalização de comportamentos considerados "aceitáveis" ou "desejados".

Dessa forma, a tecnologia da segurança interfere no direito fundamental à liberdade e à interação do sujeito em suas práticas sociais, uma vez que, ao engendrar todo um aparato de vigilância, regulariza-se uma estratégia não apenas direcionada para a repressão à violência e a manutenção da segurança; legitima-se, sobretudo, um audacioso mecanismo de controle social.

Nesse contexto, reiteramos que, por antagonismo, o indivíduo abdica de seu direito à liberdade, substituindo-o por uma pretensa ideia de proteção. $\mathrm{O}$ modelo de segurança pautado no conceito de vigilância e monitoramento ininterrupto, a partir de um aparato tecnológico de coleta de dados, instaura mecanismos que potencializam uma sociedade de controle. A proliferação de ferramentas disponibilizadas pela tecnologia da informação, ainda que disseminem uma pretensa ideia de segurança e proteção, metaforicamente, remete-nos ao arquétipo do panóptico de Bentham (2000). Assim, de 
forma profética reverbera a icônica e oportuna elocução de Foucault (2002[1975]): “o preço da liberdade é a eterna vigilância".

\section{Considerações finais}

A dialética que se estabelece entre a sociedade e a tecnologia configura, cada vez mais, uma intrínseca e tênue relação especialmente no que tange às questões éticas no emprego de artefatos de segurança. A banalização da violência e a crescente sensação de insegurança autorizam o desenvolvimento e a proliferação de um aparato tecnológico que estabelece um conceito de espaço urbano monitorado, controlado e pautado na vigilância ininterrupta e onipresente, em prol de uma suposta ideia de proteção.

A intensificação no emprego de tecnologias de monitoramento do indivíduo provoca significativas alterações nas práticas sociais, visto que se pautam na ação de vigiar, regular e padronizar comportamentos, de forma que o sujeito se torna subserviente à autoridade impetrada pela técnica.

Por antagonismo, destacamos o posicionamento acrítico de considerável parcela da sociedade que assume um comportamento passivo diante das imposições tecnológicas, as quais se materializam através de mecanismos sutis de coerção, bem como pelos artefatos de vigilância, controle e interdição, que são construídos e nela colocados em funcionamento.

Esse trabalho se situa nesse contraponto entre a submissão e a resistência, pois não se pode conceber um sujeito submisso a práticas mecanizadas, desumanizadas e disciplinadas pela tirania da tecnologia sobre a vida social.

A tecnologia da informação é fundamental na implementação da segurança, porém, há que se refletir sobre seu papel na sociedade contemporânea de forma que as inovações tecnológicas, pautadas em fatores éticos e morais, possam ser compreendidas como fator de progresso e promoção social, não como meros mecanismos de manipulação, vigilância, intervenção e controle do indivíduo.

\section{Referências bibliográficas}

ALTHUSSER, L Aparelhos Ideológicos de Estado. $3^{\text {a }}$. edição. Rio de Janeiro: Edições Graal, (1987 [1971).

BENTHAM, J. O panóptico. [Organização e tradução de Tomaz Tadeu da Silva]. Belo Horizonte: Autêntica, 2000.

BRUNO, F. Dispositivos de vigilância no ciberespaço: duplos digitais e identidades simuladas. Revista Fronteira, São Leopoldo/RS, v. VIII, p. 152-159, 2006. 
FONSECA, M.A. da. Michel Foucault e a constituição do sujeito. $3^{\text {a }}$. ed. São Paulo: Educ. 2011.

FOUCAULT, M. Vigiar e punir. $28^{\mathrm{a}}$. ed. Petrópolis: Vozes, (2002 [1975]).

GUNDALINI, B.; TOMIZAWA, G. Mecanismo disciplinar de Foucault e o panóptico de Bentham na era da informação. ANIMA [Revista Eletrônica do Curso de Direito das Faculdades OPET]. Curitiba, PR, Ano IV, nº 9, jan/jun 2013.

ORLANDI, E.P. Discurso e texto: formulação e circulação dos sentidos. $2^{a}$. ed. Campinas: Pontes, 2005.

A contrapelo: incursão teórica na tecnologia: discurso eletrônico, escola, cidade. RUA [Revista do Laboratório de Estudos Urbanos do Núcleo de Desenvolvimento da Criatividade, online], $\mathrm{n}^{\circ}$. 16, v. 2, 2010.

A linguagem e seu funcionamento: as formas do discurso. $6^{a}$. ed. Campinas: Pontes, 2011

ORWELL, G. 1984. 11ª . ed. São Paulo: Companhia Editora Nacional, 1978.

MENDONÇA, K. Assentamentos da memória: (re)construções de memória discursiva na revista Veja. Recife: Unicap, 2004.

PÊCHEUX, M. Analyse Automatique du Discours. Paris: Dunod, 1978 [1969].

[1975]. Semântica e discurso. Uma crítica à afirmação do óbvio. Campinas: Ed. da Unicamp, 1988.

ROSA, J.G. Grande Sertão: Veredas. 11ª . ed. Rio de Janeiro: José Olympio, 1976.

SCURO NETO, Pedro. Manual de sociologia geral e jurídica. $4^{\mathrm{a}}$. ed. São Paulo: Saraiva, 2000.

TERCEIRO, J.B. Sociedad digital: del homo sapiens al homo digitalis. Madrid: Alianza Editorial, 1996.

WINNER, L. La ballena y el reactor: un búsqueda de los limites en la era de la alta tecnologia. Barcelona: Gedisa, 1987 [1986].

Sites:

- <http://siesesp.org.br/noticia/100/2015-03-05/big-brother-da-vida-real-sao-paulopossui-mais-deummilhao-de-cameras-de-vigilancia>; acesso em setembro de 2015.

- $\quad$ http://revistasecurity.com.br/blog/sao-paulo-tem-mais-de-1-milhao-de-cameras-deseguranca/>; acesso em outubro de 2015. 
Artigo recebido em: junho de 2016.

Aprovado e revisado em: julho de 2016.

Publicado em: agosto de 2016

\section{Para citar este texto:}

CAIXETA, João Roberto. Da tecnologia da informação à construção de um conceito de segurança. Entremeios [Revista de Estudos do Discurso], Seção Temática [Os discursos sobre segurança em meio a políticas e processos de significação], Programa de Pósgraduação em Ciências da Linguagem (PPGCL), Universidade do Vale do Sapucaí, Pouso Alegre (MG), vol. 13, p. 213-229, jul. - dez. 2016.

DOI: http://dx.doi.org/10.20337/ISSN2179-3514revistaENTREMEIOSvol13pagina231a247 